\title{
Librarians in the Pursuit of Open Practices
}

\author{
Quill West \\ Pierce College, CWest@pierce.ctc.edu
}

\section{Editors' Commentary}

Any serious book on open would be incomplete without the inclusion of the librarian point of view. Libraries have long been repositories of learning that are strongly aligned with the open philosophy. In this chapter, author Quill West speaks to the lofty aspirations of open education. Refreshingly, her commentary is as pragmatic as it is idealized. She offers practical insights into the various ways that faculty stumble over open. West is a realist in her admission that not all open materials will satisfy every course learning outcome. Deficits, where they exist, can often be addressed but many faculty are not certain exactly how to do this. She views openness - ranging from publishing open materials to giving attribution to othersas a competency that can be learned.

Do you remember that day, or hour, or moment in your educational career when you first turned to a librarian for help? Librarians have helped us find materials when research got difficult. They helped us recreate our reference lists when we lost track of citations. They cared for the spaces, books, databases, and information tools that gave us refuge when studying. As we grow in the academic professions, librarians continue to offer those valuable information skills in planning classes, researching professional projects, and supporting student learning initiatives. Basically, librarians are all-around, interdisciplinary, learning-centered professionals who encourage the best teaching and learning

How to cite this book chapter:

West, Q. 2017. Librarians in the Pursuit of Open Practices. In: Jhangiani, R S and Biswas-Diener, R. (eds.) Open: The Philosophy and Practices that are Revolutionizing Education and Science. Pp. 139-146. London: Ubiquity Press. DOI: https://doi.org/10.5334/bbc.k. License: CC-BY 4.0 
by providing services meant to challenge people to interact with information critically and responsibly.

This piece runs the risk of being an ode to the virtue of librarianship, but I believe that to understand the value of librarians in your open practice, you must see the value of librarians in the academy. In fact, as an open librarian I find it difficult to tease out the differences between my work in open education and the professional practice of librarianship. At my core, though, I want to express one simple truth:

Your institutional library team should be one of your first calls when you decide to explore open education for the first time, just as it was natural to turn to your librarian the first time that you couldn't find a resource that you needed for a particular assignment.

\section{Open Practice - Open Values}

Open education is a philosophy that seeks to create equal access to education through lowering costs and increasing relevance of materials used in teaching and learning. While that is a generous and timely goal, the actual professional practice of adopting and adapting open materials, indeed even creating open materials, is part of a larger practice where an individual engages in open as a way of designing, teaching, and distributing a course. The ideals promised in open education are achieved when we practice the application of six open habits until they are a part of the way we live our professional lives. While open librarians often encourage teachers and learners to respect many of the principles of open education, sometimes it is hard to know proven practices that lead to easier course creation. We achieve openness by exploring and encouraging the six habits of open practice: sharing, early drafting, supportive feedback, studying licenses, giving credit, and putting students at the center.

\section{Sharing}

Sharing is an art that depends on the ability to know when to share something, and whether it is useful to the people we are sharing with. Moreover, sharing can be vulnerable and uncomfortable for many reasons.

First, most academics spend years learning the value of intellectual property and it is difficult to 'give it away'. However, in my own practice I have often reminded myself that sharing isn't giving something away. By its very nature knowledge cannot be given away, because the person giving retains the knowledge even as she passes it to someone else. Indeed, sharing our knowledge is a central piece of what instructors do every day. However, it oversimplifies the issue to ignore that intellectual property does have economic value in some 
instances. When I began sharing my works with open licenses, I balanced the potential future value of my creative work against the immediate, and definite, value of a community of people to help improve and grow the materials that I share, and I decided that sharing was of greater value to me. I have asked colleagues who are concerned over loss of possible future royalties to consider how much effort they will expend to turn their current work into a resource that a publishing company might be interested in, and how few textbook authors actually make significant royalties on their textbooks, and then I ask them to weigh those ideas against the power of a community of users and adapters. Usually the community ends up having more significance in the current life of the creator.

Another concern of most people considering sharing their openly licensed work is that adapters could use the work in a context which isn't intended, or that the adaptation could get information wrong. It's true once a work has been shared the original creator has almost no control over what is done with it. Another teacher could remix your work in a way that you would disagree with. An adapter could misrepresent you or get your work wrong. Reputation is one of the major contributing factors to hiring and promotion, particularly in academic settings, so the risk of having one's work altered without permission is a serious one. However, the other side of this argument is that you keep your work pristine, and safely in your own computer only to be shared with students, and no one ever sees your work. I try to help my colleagues see that rules surrounding adaptation and attribution of openly licensed work asks the adaptor to describe how the work was altered. Also, an adaptation always includes a link back to the original work. I also try to remember that even if something is published with the standard copyright protections, there is no protection from being misquoted or taken out of context. Once, I tried to talk a faculty member into sharing an extensive collection of handouts that she had prepared. She was worried that people would revise her work, and make it less effective. After several weeks of discussing her worries over sharing her work, and having it changed, she finally decided to openly license the handouts. I asked her what changed her mind, and she told me that it was actually a student. The student annotated and wrote notes all over the handout, and then passed it to a fellow student. She realized that the student, a complete newbie to her field, had just improved the original design by making it more accessible to his classmate. She wondered what useful adaptations others teachers of her discipline might make to improve the final document.

Another difficulty that I have encountered when encouraging others to share is predicting what others will want. Teachers, in particular, often say a variation of the following to me: 'No one could use what I do in my class, because I do it my way.' How do you know when you should go to the trouble of making something available, especially when you don't know how useful it will be to other people? First, I always ask people, 'How do you know no one else can use it? Maybe you're revolutionizing teaching this topic and no one else will ever know because you aren't sharing it.' However, that answer might be overly optimistic. 
Instead, I try to think in terms of asking for an expert to help decide what might help others. Here again, librarians are useful people. Librarians most often work with your colleagues across multiple disciplines, and they most definitely work with students from across your institution. They can help you to see if your material might be useful to others.

Finally, sharing is made more difficult by not knowing how to get your work into a sharing space. The logistics of moving a creative work from your computer, course management system, notebook, canvas, or video camera to a space where others can find and use it is one of the more frustrating issues when you seek to share. I have faced the same challenges in my career. One of the biggest talents a librarian can bring to your sharing is a professional interest in curating and sharing knowledge. As a librarian I have had to invent low and no-cost strategies for sharing my own as well as colleagues' works in front of a worldwide stage. At larger institutions the advent of institutional repositories and digital scholarship departments means that space and encouragement for sharing are more prevalent and respected. Check with your library, because chances are someone might be able to help you to share your work more widely.

\section{Early Drafting}

One of the biggest gifts that open can bring to your educational practice is the permission to stop being a perfectionist. Educators put a lot of pressure on ourselves to create perfect works. We don't submit journal articles to peer review until they have been internally vetted, and we never expect to be published if our work doesn't meet a gold standard. We rely on extensive editorial processes to help us pick over our creative works so that they will be ready for our colleagues to view. The review process is necessary and important in academic scholarship. In fact, the review process is so necessary in higher education that one of the common criticisms of early open materials is that they didn't include that process. However, I would argue that this is a value of the open education field because instead of limiting the process to a select few people who will be responsible for vetting a work that might be intended for an entire field, open education resources are vetted by everyone in the community. Some open materials are reviewed, revised, reworked, remixed, and continually updated by an entire community of people who are passionate about maintaining the resource.

It's important to break here to note that some open projects, such as OpenStaxCollege, BC Open Textbook Project, and NOBA have implemented extensive review and editorial processes. These projects should be celebrated, and relied on when possible. However, most individuals seeking to participate in open resources by contributing lessons, handouts, lectures, notebooks, visuals, tutorials, and writings won't find that kind of support easily. I will note however 
that librarians at your institution might be a useful place to find out if there are extensive projects like the ones described that your work could fit into. A growing number of librarians in the world are following open creation and adoption projects.

As a creator the gift that open education brings to you is simply: it's okay to not be perfect. This isn't to say that you shouldn't proofread, or ask local colleagues to read and give input on your open materials before you release them. It does mean, however, that you can start to share things earlier and more often.

I see faculty embodying this ideal of early drafts on a regular basis. A great example is the work that faculty at Pierce College at Joint Base Lewis-McChord (JBLM; a military base) has begun sharing recently. They used the Lumen Learning platform to revise, remix, and write a series of resources for Introduction to Nutrition. As a strategy in the design phase of that work, the faculty team completed the textbook enough to teach the first quarter with it, and then they released the book through librarians, instructional designers, and open project managers. The goal was to ask for the community for suggested revisions and additions. Eventually the book will be revised, and hopefully the community of teachers of Nutrition will help with revisions.

\section{Supportive Feedback}

If one of the habits of open educators is to release work before it goes through an extensive review process, then it falls to the community using the work to give respectful, honest, supportive feedback that will move the general work forward. As educators adopt open materials it is increasingly helpful to let the creator know what materials you are adopting, how you are using those resources, and any remixing or revision you might have done with the work. I'm fond of telling students and faculty that we don't know if a work needs to be better if no one tells us.

\section{Studying Licenses}

You don't have to be a copyright expert to apply open licensing to your own work. You do, however, need ensure that you are using other peoples' works ethically and legally. An essential part of your open practice should be examining works for licensing and usage rights. While open licenses are designed for ease of interpretation, the implications of mixing and matching licenses can be frustrating.

Most institutions have librarians who have studied how copyright and open licensing impacts their institutions. Cable Green's chapter in this book is a helpful description of open licenses and their use, which you might consider sharing with your library team. If your local library team doesn't have ready 
expertise in open licensing, they probably have a network of people who can help them to address your question.

\section{Giving Credit}

Crediting original authors of ideas is not a new concept in higher education. In fact in libraries all over the world there are students creating American Psychological Association (APA) citations right now. However, it isn't a normal practice to include attributions on all of our slides or in all of our writings. We are used to crediting ideas, but not necessarily artifacts of those ideas. There are a series of best practices for writing and including attributions on openly licensed works.

I encourage faculty to develop a practice of always including an attribution on every creative work adapted. More than once in my academic career I have been tasked with going back to add attributions to works where they are missing. My least favorite conversation to have with a faculty adopter of open materials is that material has to be omitted or substituted because the attribution cannot be verified. That is why it is incredibly important to start with the right attributions to begin with.

Building a consistency around attributions and recording rights is a habit that all users of open materials should grow into. Certifying in-house created and remixed open materials is also an important part of the attribution process. Librarians can be helpful allies in reviewing and verifying attributions and ethical use of openly licensed materials.

\section{Putting Students at the Center}

Students, their learning, and their access to creative, energizing, and engaging educational experiences is at the center of most open education projects. Teaching practices should always consider how students interact with materials, lessons, assignments, and one another. When reviewing open materials, I have always tried to picture the students who will be asked to use the resources. I try to picture myself as a reference librarian tasked with explaining the resource to a student. What kinds of questions will the student arrive at? How will the student internalize the concepts presented? Will the student find rewarding experiences in doing the assignments that surround the open material? These questions guide the process of evaluating and enhancing open materials to fit the instructor's teaching practice.

Librarians are in unique places at our institutions, because they often interact with students across disciplines. In my experience, librarians are usually the best people to help clarify assignment prompts because they have so much face-time with students of varying abilities and academic experiences. While 
instructors spend several hours over the course of a quarter with a group of students, librarians often spend one on one time helping students from across the institution to define and articulate information needs, so that students can successfully complete course assignments.

Another level of putting students at the center of open education initiatives is inviting student voice to the planning and implementation of overall projects. Librarians can assist in this conversation, because students often see libraries as safe places to share opinions and ideas. Librarians and libraries have professional values of service and support of our patrons. These incredibly central professional ethics have built a decades-old culture of safe spaces, which can be leveraged carefully to encourage students to share ideas for bettering their experiences. At some institutions the average student voice is illusive, no matter how hard we try to capture it. In some cases, librarians can help to solicit the quieter student voices. I have seen students tell librarians about personal financial issues, challenges in access to basic services, and issues regarding college readiness. Admittedly, student service offices can serve the same purpose. However, librarians are in a position to bridge both student service and academic approaches in outreach to students. When possible and where appropriate, librarians should be included in planning to invite the student voice into open education.

\section{Open Education and Information Competency}

One of the most exciting elements of open practice is the opportunity to improve teaching and learning. Adopting open materials can include a process of examining and improving pedagogy. Early in my open education practice I realized that sometimes open materials will fall short in terms of total coverage of course outcomes. This posed little threat to me, because as a librarian I knew that there were other ways to encourage students and instructors to fill in content. Information competencies, and assignments designed to build both content information and information skillsets, are a way to further student learning and meet course outcomes. An information competency assignment might ask students to research and summarize major concepts of course outcomes. By conducting research on their own, students are more likely to remember course content. Also, they are encouraged to see that knowledge building and information creation is a process that includes an interaction between knowledge seekers and information sources. I'm hardly the only librarian to arrive at the conclusion that open education is a way to encourage students to interact with a cycle of information that includes the ongoing process of creating, evaluating, and incorporating new knowledge into existing sources. In fact my voice is one of many advising open practitioners to include information competency assignments as part of growing pedagogical approaches to support open education. 


\section{Conclusion}

Information and using it to grow knowledge and wisdom is a central part of what being a student is all about. Open practices reinforce this idea by making the information creation process a little more transparent to students. Instead of being faced with a pre-packaged, comprehensive collection of readings that students often interpret as the 'learning' of a course, open materials ask the students to invest in study practices that include active decision-making about learning materials. In this way open practices align more completely with missions of libraries because it is a central value of our profession that all people need to develop information competency. Also of central value to our profession is the belief that sharing resources - books, computers, space - improves the larger community. Open education is a growing educational movement where these two values meet. By sharing our expertise in curating resources, building information competency, serving students and institutions, and in moving across disciplinary silos, librarians can help our institutions to embrace change that will open access for many of our students.

Most academics love librarians because librarians are dedicated to stripping the confusion and mystery out of finding and using information. Librarians make being a student easier, which helps students to meet their goals. However, the truly savvy professor knows that their institutional library team also makes teaching easier. 